Annales Geophysicae (2001) 19: 1133-1139 (c) European Geophysical Society 2001

\title{
Thermospheric zonal temperature gradients observed at low latitudes
}

\author{
P. R. Fagundes ${ }^{1}$, Y. Sahai ${ }^{2}$, and J. A. Bittencourt ${ }^{2}$ \\ ${ }^{1}$ Universidade do Vale do Paraiba / UNIVAP, Av. Shishima Hifumi, 291, CEP 12244-000, São José dos Campos, Brazil \\ ${ }^{2}$ Instituto Nacional de Pesquisas Espaciais - INPE, CP: 514, CEP 12201-970, São José dos Campos, Brazil
}

Received: 16 October 2000 - Revised: 8 June 2001 - Accepted: 20 June 2001

\begin{abstract}
Fabry-Perot interferometer (FPI) measurements of thermospheric temperatures from the Doppler widths of the OI $630 \mathrm{~nm}$ nightglow emission line have been carried out at Cachoeira Paulista $\left(23^{\circ} \mathrm{S}, 45^{\circ} \mathrm{W}, 16^{\circ} \mathrm{S}\right.$ dip latitude), Brazil. The east-west components of the thermospheric temperatures obtained on 73 nights during the period from 1988 to 1992 , primarily under quiet geomagnetic conditions, were analyzed and are presented in this paper. It was observed that on $67 \%$ of these nights, the temperatures in both the east and west sectors presented similar values and nocturnal variations. However, during $33 \%$ of the nights, the observed temperatures in the west sector were usually higher than those observed in the east sector, with zonal temperature gradients in the range of $100 \mathrm{~K}$ to $600 \mathrm{~K}$, over about an $800 \mathrm{~km}$ horizontal distance. Also, in some cases, the observed temperatures in the east and west sectors show different nocturnal variations. One of the possible sources considered for the observed zonal temperature gradients is the influence of gravity wave dissipation effects due to waves that propagate from lower altitudes to thermospheric heights. The observed zonal temperature gradients could also be produced by orographic gravity waves originated away, over the Andes Cordillera in the Pacific Sector, or by dissipation of orographic gravity waves generated over the Mantiqueira Mountains in the Atlantic sector by tropospheric disturbances (fronts and/or subtropical jet streams).
\end{abstract}

Key words. Atmospheric composition and structure (airglow and aurora; thermosphere - composition and chemistry) Ionosphere (equatorial ionosphere)

\section{Introduction}

The OI $630 \mathrm{~nm}$ nightglow emission comes from the $\mathrm{O}_{2}^{+}$dissociative recombination process $\left(\mathrm{O}_{2}^{+}+\mathrm{e} \rightarrow \mathrm{O}^{*}+\mathrm{O}\right)$ in the bottomside of the F-region $(250-300 \mathrm{~km})$. By measuring the Doppler shifts and widths of the OI $630 \mathrm{~nm}$ nightglow emis-

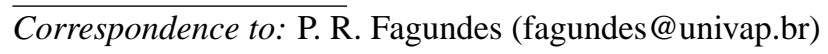

sion line, using a Fabry-Perot interferometer, it is possible to infer the thermospheric winds and temperatures, respectively, at the heights of the OI $630 \mathrm{~nm}$ emission layer. Thus, the Fabry-Perot interferometer has become a powerful instrument to study the thermosphere dynamics and the thermosphere/ionosphere coupling at high, mid and low latitudes (Sipler et al., 1982; Hernandez and Roble, 1984; Rees et al., 1984; Yagi and Dyson, 1985; Biondi et al., 1990; Sahai et al., 1992a, 1992b; Sastri and Ranganath, 1994; Gurubaran et al., 1995; Fagundes et al., 1995a, 1995b, 1995c, 1996a, 1996b, 1998; Bittencourt et al., 1997; Meriwether et al., 1996, 1997).

Fabry-Perot interferometer (FPI) measurements of the OI $630 \mathrm{~nm}$ nightglow emission line have been carried out at Cachoeira Paulista $\left(23^{\circ} \mathrm{S}, 45^{\circ} \mathrm{W}, 16^{\circ} \mathrm{S}\right.$ dip latitude), Brazil, during the period of 1988 to 1992 , thereby allowing a study of several important features of the thermosphere under geomagnetically quiet or disturbed conditions (Sahai et al., 1992a, 1992b; Fagundes et al., 1995a, 1995b, 1996a, 1996b, 1998; Bittencourt et al., 1997). Sahai et al. (1992a, 1992b) presented important features of the seasonal behaviour of the thermospheric wind velocities and temperatures during the rapidly increasing phase of the solar flux (March 1988, $\mathrm{F}_{10.7}=113.8$ and December 1989, $\mathrm{F}_{10.7}=206.3$ ) at Cachoeira Paulista. Also, Fagundes et al. (1996a, 1998) studied the thermosphere/ionosphere coupling during quiet and disturbed geomagnetic conditions, using the observed wind and temperature gradient temporal variations to infer the plasma drift velocities.

Although optical instruments have been widely used to study the upper atmosphere for nearly half a century, the observations of thermospheric neutral winds and temperatures at low latitudes, using a FPI, are still recent and are providing interesting and novel scientific results. Fagundes et al. (1996a, 1998) observed unusually large thermospheric zonal temperature gradients at Cachoeira Paulista $\left(23^{\circ} \mathrm{S}\right)$, Brazil, and Meriwether et al. (1996, 1997) observed both zonal temperature and wind gradients at Arequipa $\left(16.5^{\circ} \mathrm{S}\right)$, Peru. 
Table 1. A list of observation dates, solar-geomagnetic conditions temperature gradients and mean nocturnal temperature, considered in this study

\begin{tabular}{ccllllllcc}
\hline Date & $\begin{array}{c}\mathrm{F}_{10.7} \\
{\left[\mathrm{~W} / \mathrm{m}^{2} \mathrm{~Hz}\right]}\end{array}$ & & & $\mathrm{Kp}$ & & $\begin{array}{c}\text { Temperature } \\
\text { gradients (west/east) }\end{array}$ & $\bar{T}$ (west - east) \\
\hline 22 March 88 & 117.6 & $1-$ & $1-$ & $1-$ & $0+$ & $1+$ & No & 995 \\
08 December 88 & 164.1 & 1 & $1+$ & $2-$ & $0+$ & $0+$ & Yes & 1416 \\
03 May 89 & 190.6 & $2-$ & $1+$ & $4+$ & $4-$ & $2+$ & No & 1241 \\
26 October 89 & 171.7 & 5 & $4+$ & $4+$ & $3+$ & $3+$ & Yes & 1306 \\
11 November 89 & 249.1 & 4 & $4-$ & $3+$ & 3 & $2+$ & No & 1372 \\
10 April 91 & 223.6 & $1-$ & $1+$ & 1 & 1 & 1 & Yes & 1472 \\
07 July 91 & 226.1 & $2+$ & $3-$ & $2+$ & $3-$ & $4-$ & Yes & 1009 \\
09 August 91 & 154.6 & 3 & $3-$ & $1+$ & $2+$ & 3 & Yes & 816 \\
10 August 91 & 145.7 & $1+$ & $2-$ & $4+$ & 4 & 4 & Yes & 841 \\
05 September 91 & 166.2 & 3 & $3-$ & 3 & $4+$ & $3-$ & No & 1183 \\
07 September 91 & 177.1 & $3-$ & $1+$ & $4-$ & $3+$ & $2+$ & No & 1244 \\
28 January 92 & 230.6 & $3-$ & 2 & $2+$ & $3+$ & $3+$ & Yes & 1059 \\
04 April 92 & 154.0 & 3 & $2-$ & 3 & 2 & $3-$ & No & 982 \\
27 May 92 & 117.7 & $2+$ & $2-$ & 2 & $2-$ & $3+$ & No & 756 \\
\hline
\end{tabular}

In this paper, we present a study of the occurrence and possible sources of the observed thermospheric zonal temperature gradients recorded at Cachoeira Paulista, using a series of 73 nights of observations (the nights studied had more than 3 hours of measurements) obtained during the period from 1988 to 1992, primarily under quiet geomagnetic conditions and mid-high solar activity. It should be pointed out that, to a certain extent, uniformity of temperature in the thermosphere is expected due to its high viscosity. The MSIS-90 model (Hedin, 1991) predicts very small east-west thermospheric temperature gradients for low latitudes.

\section{Instrumentation}

The FPI characteristics have been presented by Sahai et al. (1992a and 1992b). The parallelism adjustment of the etalon ( $15 \mathrm{~cm}$ diameter) and the wavelength scanning are performed by three optically contacted piezoelectric pads. Also, the temperature of the etalon is controlled $\left( \pm 0.1^{\circ} \mathrm{C}\right)$. A 64 channel digital analyzer is used to scan the interferometer in wavelengths and several scans are added in order to increase the signal-to-noise ratio. The number of additions depends on the ability to maximize the OI 630 intensity level without losing time resolution. The error in the inferred Doppler temperature is $\pm 40^{\circ} \mathrm{C}$ for an OI $630 \mathrm{~nm}$ emission intensity level of $200 \mathrm{R}$. The peak height of the OI $630 \mathrm{~nm}$ emission is around the 240 to $270 \mathrm{~km}$ altitude. Since the FPI can observe in the four cardinal points (north, south, east and west) at an elevation angle of $30^{\circ}$, the zonal horizontal distance between the observed points is about 800 to $900 \mathrm{~km}$. It should be mentioned that we do not have measurements in the zenith position, and the zonal and meridional winds are calculated from the differences between east-west and northsouth peak wavelength displacements of the observed fringe profiles (Sahai et al. 1992a).

\section{Results and discussion}

During the period of 1988 to 1992 , mostly under quiet geomagnetic conditions and mid-high solar activity, a total of 73 nights of thermospheric temperature observations has been analyzed. One of the prominent features in the observed thermospheric temperatures at low latitudes (South American sector) is the occasional presence of strong thermospheric zonal temperature gradients. This feature has been reported by two independent research groups from observations carried out in two different locations in the South American sector. The first report was based on observations made at Cachoeira Paulista $\left(23^{\circ} \mathrm{S}, 45^{\circ} \mathrm{W}\right.$, Atlantic side) by Fagundes et al. (1996a) and the second one was based on observations made at Arequipa $\left(16.5^{\circ} \mathrm{S}, 71.5^{\circ} \mathrm{W}\right.$, Pacific side), Peru, by Meriwether et al. (1996, 1997). Table 1 lists the dates of the selected nights presented in this study, the mean nocturnal temperature, the observed temperature gradients and the solar-geomagnetic conditions. We consider the existence of a significant temperature gradient when there is a continuous difference that is greater than $100 \mathrm{~K}$ in the thermospheric temperatures between the east and west sectors (over about $800 \mathrm{~km}$ horizontal distance) for more than three hours.

Figure 1 presents a map of South America showing the locations of the Andes (west side) and Mantiqueira (east side) Mountains. Also, the sub-ionospheric points $(\sim 270 \mathrm{~km}$ altitude) of the FPI beams in the east-west direction are marked on the map for both the Cachoeira Paulista and Arequipa observatories.

The temperature gradients are more often and prominently observed in the zonal direction at Cachoeira Paulista, but the meridional temperature gradients were also observed on a few occasions. In this paper, we shall concentrate our analysis and discussion only on the zonal direction observations. Figures 2 and 3 show the temperatures observed in the east and west directions for a few representative nights with and 
Table 2. Number of nights analyzed with/without thermospheric zonal temperature gradients for three solar flux levels

\begin{tabular}{ccccc}
\hline $\mathrm{F}_{10.7}\left[\mathrm{~W} / \mathrm{m}^{2} \mathrm{~Hz}\right]$ & $<150$ & $150-200$ & $>200$ & Total of Nights \\
\hline Number of Nights & 12 & 32 & 29 & $73(100 \%)$ \\
With Gradients & $4(33 \%)$ & $9(28 \%)$ & $11(37 \%)$ & $24(33 \%)$ \\
Without Gradients & $8(67 \%)$ & $23(72 \%)$ & $18(63 \%)$ & $49(67 \%)$ \\
\hline
\end{tabular}

without temperature gradients. The nighttime temperature variations predicted by the MSIS-90 model (Hedin, 1991) are also presented in Figs. 2 and 3 for some nights and for two different longitudes $\left(23^{\circ} \mathrm{S}, 41^{\circ} \mathrm{W}\right.$, closed square; and $23^{\circ} \mathrm{S}, 49^{\circ} \mathrm{W}$, open circle) at the $270 \mathrm{~km}$ altitude, but at Cachoeira Paulista local time. These two locations are close to the positions at which the FPI observes the temperatures in the east and west directions, respectively, from Cachoeira Paulista. Notice that the MSIS-90 model gives, in general, a very small east-west temperature gradient $(\sim 25 \mathrm{~K}$ over a range of $800 \mathrm{~km}$ ). Sahai et al. (1992) have reported that the observed thermospheric temperatures at Cachoeira Paulista are in good agreement with the MSIS-86 model for the winter and equinox seasons. However, the MSIS model results primarily represent average conditions and do not exhibit the day-to-day variability present in the thermospheric temperatures. Table 2 shows the details of all the nights analyzed (73 nights) with and without zonal temperature gradients as a function of solar activity.

\subsection{Observations without temperature gradients}

On most of the nights on which thermospheric temperatures were observed, during the period from 1988 to 1992, the temperature to the east and to the west directions at Cachoeira Paulista presented similar nighttime features and magnitude. Figure 2 shows the temperatures observed in the east and west directions for some representative nights without temperature gradients. On $49(67 \%)$ out of the 73 nights of observation, the temperature behaviour was similar to that shown in Fig. 2.

It is noted that the observed temperatures in the west and east sectors presented very similar nocturnal variations during these nights. Also, this behaviour remains the same in both sectors $\left(\mathrm{T}_{E}\right.$ over the sea and $\mathrm{T}_{W}$ over the continent) when the observed temperatures presented either smooth nighttime variations (e.g. 22 March 1988) or wave-like variations (e.g. 11 November 1989). On the nights when the thermospheric temperature variations showed wave-like structures, it is seen that the temperatures in both sectors presented a similar amplitude of variation (100 K to $400 \mathrm{~K}$ ). These wave-like variations could possibly be caused by the presence of gravity waves at the thermospheric heights, in periods of a few hours.

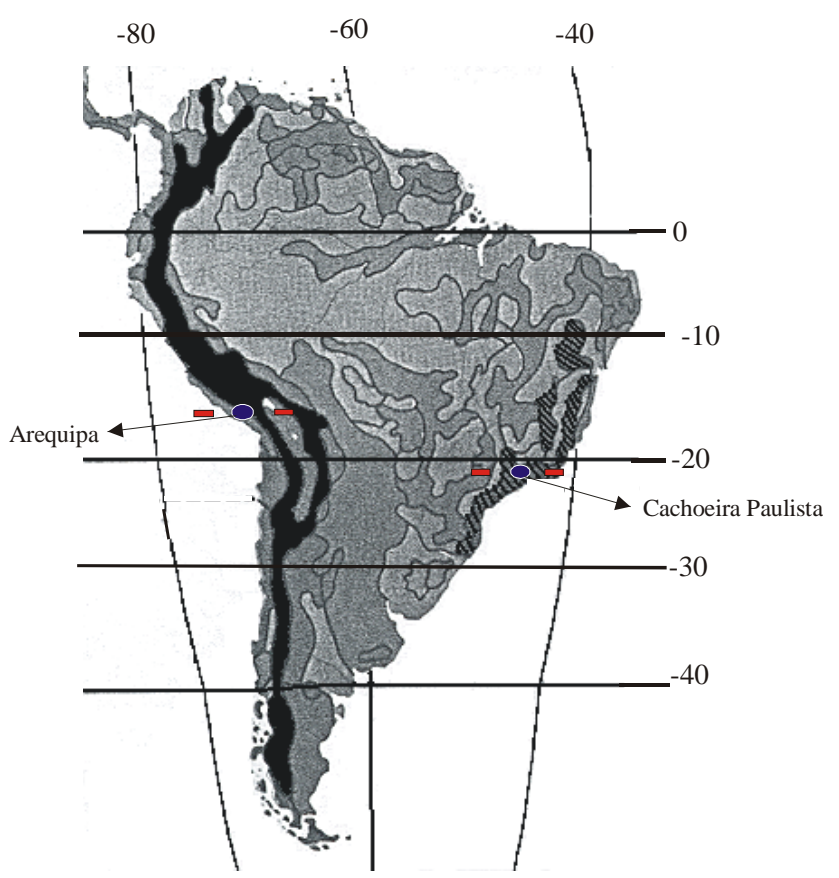

Fig. 1. Map of South America showing the location of the Andes Cordillera (left side - black) and of the Mantiqueira Mountains (right side - hatched) and the zonal sub-ionospheric points $(\sim 270 \mathrm{~km})$ for Cachoeira Paulista and Arequipa.

\subsection{Observations with temperature gradients}

During the period studied, 24 nights $(33 \%)$ showed the presence of significant zonal temperature gradients. Table 2 shows the number of nights that presented zonal temperature gradients and the number of nights that did not, for three different levels of solar activity. It is noted that the occurrence of zonal temperature gradients is somewhat higher when $\mathrm{F}_{10.7}>200\left[\mathrm{~W} / \mathrm{m}^{2} \mathrm{~Hz}\right](37 \%)$ than when $\mathrm{F}_{10.7}$ is between $150-200\left[\mathrm{~W} / \mathrm{m}^{2} \mathrm{~Hz}\right](28 \%)$. This indicates that the occurrence of zonal temperature gradients has some dependence on solar activity level and this result agrees with that previously presented by Meriwether et al. (1997). However, we find that the occurrence of zonal temperature gradients, when $\mathrm{F}_{10.7}<150\left[\mathrm{~W} / \mathrm{m}^{2} \mathrm{~Hz}\right](33 \%)$, is similar to that when $\mathrm{F}_{10.7}>200\left[\mathrm{~W} / \mathrm{m}^{2} \mathrm{~Hz}\right](37 \%)$, but due to the small number of nights (12) when $\mathrm{F}_{10.7}<150\left[\mathrm{~W} / \mathrm{m}^{2} \mathrm{~Hz}\right]$, these results must be considered with some reservation. The number of nights analyzed when $F_{10.7}$ is between $150-200\left[\mathrm{~W} / \mathrm{m}^{2} \mathrm{~Hz}\right]$ and $\mathrm{F}_{10.7}>200\left[\mathrm{~W} / \mathrm{m}^{2} \mathrm{~Hz}\right]$ are more significant (32 and 29 


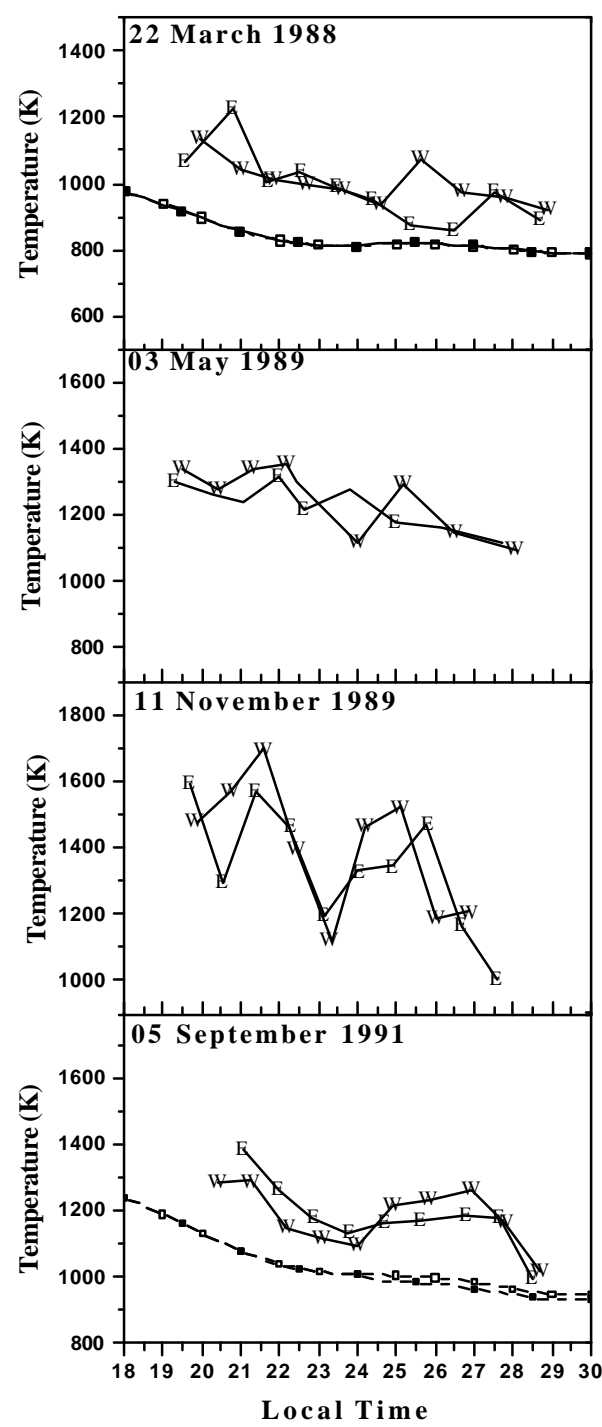

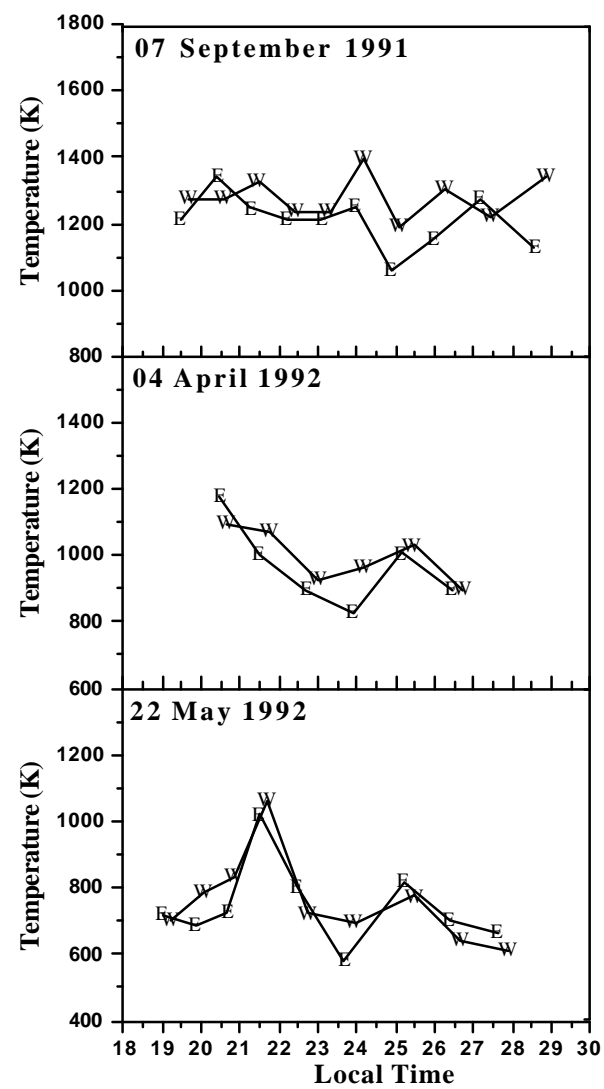

Fig. 2. Nighttime variations of the observed temperatures to the east and west, for representative nights without thermospheric zonal temperature gradients. The temperatures obtained from the MSIS-90 model are also shown for two different longitudes $\left(23^{\circ} \mathrm{S}, 41^{\circ} \mathrm{W}\right.$, closed square) and $\left(23^{\circ} \mathrm{S}, 49^{\circ} \mathrm{W}\right.$, open circle) at $270 \mathrm{~km}$ of altitude. nights, respectively), so that these results are more representative. The dependence of the observed temperature gradients on solar activity could be associated with the increase in the F-region electron density with solar activity and possible increase in the transmission of gravity waves from the lower to the upper atmosphere (Meriwether et al., 1997). It should be mentioned that Meriwether et al. (1997) observed thermospheric temperature gradients only during the winter in the high solar activity period, whereas in the present investigations, thermospheric temperature gradients occurred in all seasons with medium to high levels of solar activity.

\subsection{Possible mechanisms causing zonal temperature gradi- ents}

Meriwether et al. $(1996,1997)$ have suggested that the temperature gradients observed at Arequipa $\left(16.5^{\circ} \mathrm{S}, 71.5^{\circ} \mathrm{W}\right)$ are produced by orographic gravity wave viscosity dissipation. They have suggested that low-frequency components of orographic gravity waves are generated at low-altitudes (tro- posphere) at the Andes Cordillera and propagate vertically to thermospheric heights, where these waves are dissipated, producing a localized region of heating. Also, Meriwether et al. (1997) proposed that the temperature gradients observed at Cachoeira Paulista $\left(23^{\circ} \mathrm{S}, 45^{\circ} \mathrm{W}\right)$ (Fagundes et al., 1996a) are just a manifestation of the same heating source, since any perturbation in the thermosphere may extend farther to the east, away from the Andes, and then reach Cachoeira Paulista.

Since the thermospheric zonal wind flows eastward during the night for almost the whole year, neutral air which is heated at Arequipa could reach Cachoeira Paulista. However, this heated neutral air has to travel a distance of approximately $26^{\circ}(\sim 2600 \mathrm{~km})$ and for a typical eastward wind of $100 \mathrm{~m} / \mathrm{s}$ at thermospheric heights, this neutral air will reach Cachoeira Paulista about 7 hours later. There is no physical restriction for perturbations travelling from the Andes (Pacific) to Brazil (Atlantic), but there are some physical obstacles for its occurrence. The typical horizontal distance be- 

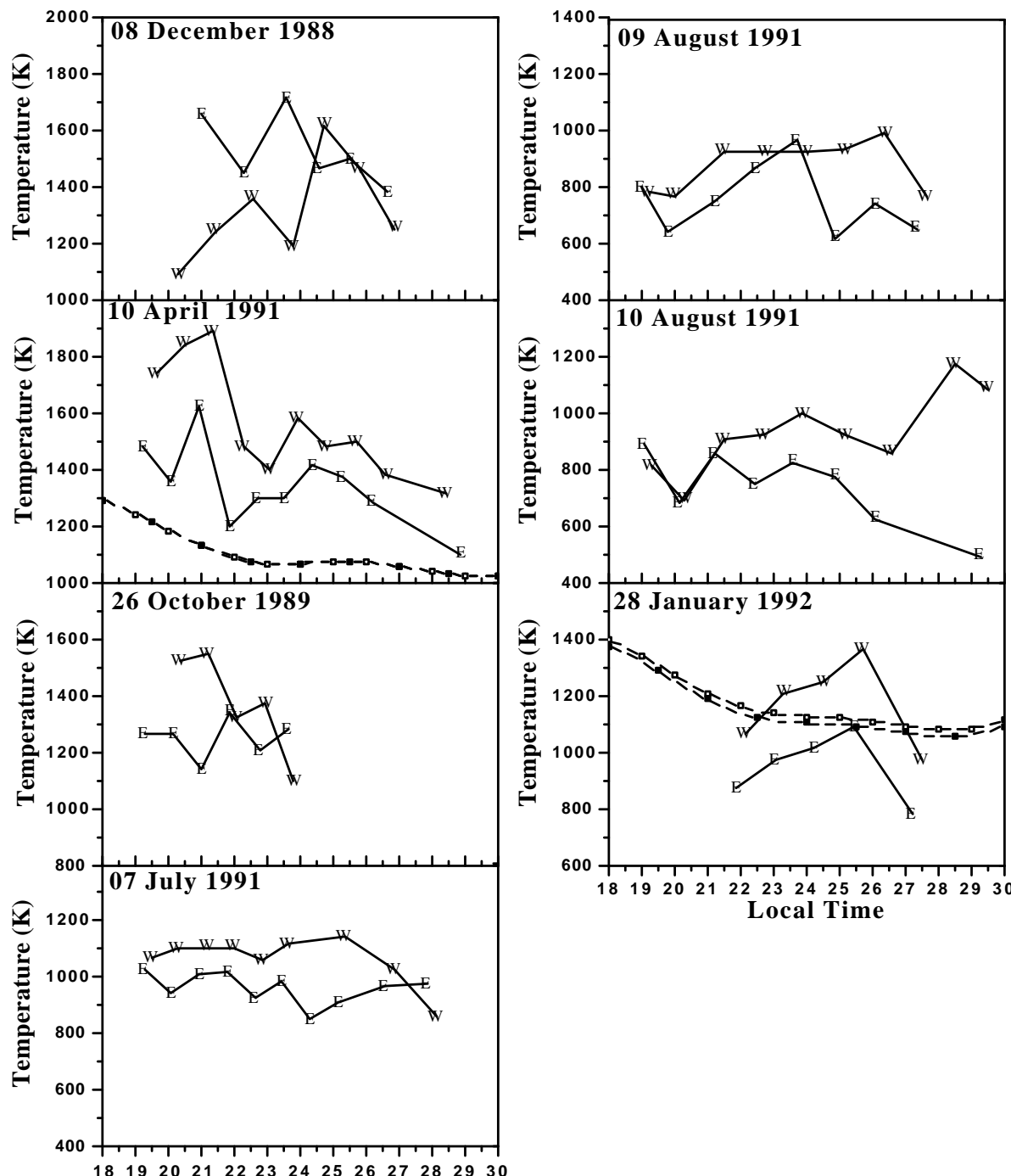

Local Time
Fig. 3. Nighttime variations of the observed temperatures to the east and west, for representative nights with thermospheric zonal temperature gradients. The temperatures obtained from the MSIS-90 model are also shown for two different longitudes $\left(230^{\circ} \mathrm{S}\right.$ $41^{\circ} \mathrm{W}$, closed square) and $\left(23^{\circ} \mathrm{S}\right.$, $49^{\circ} \mathrm{W}$, open circle) at $270 \mathrm{~km}$ of altitude tween the observed east-west sectors in FPI observations is about $800 \mathrm{~km}$. Since we are observing temperature gradients at Cachoeira Paulista of about $100 \mathrm{~K}$ to $600 \mathrm{~K}$ (Fig. 3), the neutral air flowing eastward has to lose about $12.5 \mathrm{~K}$ to $75 \mathrm{~K}$ per each $100 \mathrm{~km}$, respectively. Taking into account that the thermospheric neutral air heated at the Andes has to travel $\sim 2600 \mathrm{~km}$ to reach Cachoeira Paulista, the total temperature decrease during this long travel is estimated at $325 \mathrm{~K}$ to $1950 \mathrm{~K}$, respectively (considering orographic heating over the Andes as a point heat source). Therefore, it is possible to explain temperature gradients of the order of $100 \mathrm{~K}$ at Cachoeira Paulista by taking into account the heating produced at the Andes (Pacific sector). Nevertheless, it is almost impossible to explain the temperature gradients at $\mathrm{Ca}$ choeira Paulista which are larger than $200 \mathrm{~K}$, without taking into account other sources of localized heating. However, we have to bear in mind that the spatial structure (longitudinal/latitudinal) of orographic gravity waves generated over the Andes (which is about $300 \mathrm{~km}$ across) is not yet known.
It is, therefore, necessary to consider other possible sources of thermospheric heating in addition to that proposed by Meriwether et al. (1997) for the observations at Cachoeira Paulista. Ionospheric processes, such as ion-neutral coupling effects, could provide another source leading to thermospheric temperature gradients. However, within the ionosphere itself, the main longitudinal dependent factor is the geomagnetic field geometry or magnetosphere/ionosphere coupling. Since most of the observations reported here were obtained during relatively quiet geomagnetic conditions and the observation regions are fairly close in space, we could rule out the possibility of longitudinal variations contributing to the observed temperature gradients in ionospheric processes. Also, as mentioned by Meriwether et al. (1997), magnetic activity effects would not produce the form of localized heating which is observed.

Hines (1960) drew attention to the importance of atmospheric gravity waves at ionospheric heights. Sources for medium-scale gravity waves include tropospheric distur- 
Table 3. Details of tropospheric disturbances in the region of observation on the nights of measurements with/without thermospheric temperature gradients (Source: Climanalise, a monthly publication by INPE)

\begin{tabular}{cccc}
\hline & $\begin{array}{c}\text { \# of nights with } \\
\text { observations }\end{array}$ & $\begin{array}{c}\text { \# of days with meteorological } \\
\text { data available }\end{array}$ & $\begin{array}{c}\text { \# of days with tropospheric disturbances } \\
\text { (passage of fronts/or sub tropical jet streams) }\end{array}$ \\
\hline $\begin{array}{c}\text { Nights with E-W } \\
\text { temperatures gradients } \\
\text { Nights without E-W } \\
\text { temperatures gradients }\end{array}$ & 24 & 23 & $9(39 \%)$ \\
\hline
\end{tabular}

bances, such as the jet streams, frontal systems and penetrative convection (e.g. Bertin et al., 1978). Table 3 shows the details of the tropospheric disturbances (fronts and subtropical jet streams) present in the region close to the observation site on days with and without thermospheric temperature gradients. The Mantiqueira Mountains have several peaks as high as $2500 \mathrm{~m}$ in altitude. Thus, an additional source for some of the observed temperature gradients could be the interaction of the tropospheric disturbances with the Mantiqueira Mountains (which occupies an extensive region around $22^{\circ} \mathrm{S}, 44^{\circ} \mathrm{W}$ ), thereby producing large vertical wavelength waves that propagate upward from mountains. Zonal temperature gradients in the thermosphere at low latitudes have only been identified in the last 5-10 years and their cause is still not completely understood. More simultaneous thermospheric and ionospheric observations from regions with different topography will be important to provide additional information for a better understanding of the sources of thermospheric zonal temperature gradients at low latitudes.

\section{Conclusions}

We have analyzed thermospheric temperature variations (on 73 nights) observed at Cachoeira Paulista $\left(23^{\circ} \mathrm{S}, 45^{\circ} \mathrm{W}\right)$, during the period from 1988 to 1992 , under primarily quiet geomagnetic conditions and mid-high solar activity. The main features associated with the occurrence of thermospheric zonal temperature gradients are summarized below:

1. Of the 73 nights studied, during the period from 1988 to $1992,33 \%$ of the nights presented thermospheric zonal temperature gradients. Also, the occurrence of zonal temperature gradients have some dependence on the solar activity level and are observed in all seasons.

2. One of the possible sources for zonal temperature gradients greater than $100 \mathrm{~K}$ (over $800 \mathrm{~km}$ horizontal distance), at Cachoeira Paulista, is the heating produced in the Andes by orographic gravity waves, as suggested in a recent study by Meriwether et al. (1996, 1997). Nevertheless, it is not possible to explain the observed temperature gradients at Cachoeira Paulista larger than $200 \mathrm{~K}$, without taking into account other localized heating sources.
3. Orographic gravity waves may be generated at the Mantiqueira Mountains and their dissipation at thermospheric heights may induce a localized heating and, consequently, produce an additional source for the observed temperature gradients.

Acknowledgements. Thanks are due to Drs. V. B. Rao and P. Satyamurty for helpful discussions related to the tropospheric disturbances. Partial funding for this work was provided through the Fundação de Amparo à Pesquisa do Estado de São Paulo (FAPESP), process $N^{\circ}$ 95/09297-7 and 97/00810-8, Conselho Nacional de Desenvolvimento Cientfico e Tecnológico (CNPq) No 521243/97-1.

Topical Editor M. Lester thanks P. Dyson and another referee for their help in evaluating this paper.

\section{References}

Biondi, M. A., Meriwether, J. W., Fejer, B. G., and Gonzalez, S. A., Seasonal variations in the equatorial thermospheric wind measured at Arequipa, Peru. J. Geophys. Res., 95(A8), 12, 243-250, 1990.

Bertin, F., Kersley, L., Rees, P. R., and Testud, J., Meteorological jet stream as source of medium scale gravity-waves in thermosphere - an experimental study, J. Atmos. Terr. Phys., 40(10), 11611183, 1978.

Bittencourt, J. A., Sahai, Y., Fagundes, P. R., and Takahashi, H., Simultaneous observations of equatorial F-region plasma depletions and thermospheric winds, J. Atmos. Terr. Phys., 59, 10491059, 1997.

Fagundes, P. R., Aruliah, A. L., Rees, D., and Bittencourt, J. A., Gravity wave generation and propagation during geomagnetic storms over Kiruna $\left(67.8^{\circ} \mathrm{N}, 21.4^{\circ} \mathrm{E}\right)$, Ann. Geophysicae, 13, 358-366, 1995a.

Fagundes, P. R., Sahai, Y., Bittencourt, J. A., and Takahashi, H., Observation of thermospheric neutral winds and temperatures at Cachoeira Paulista $\left(23^{\circ} \mathrm{S}, 45^{\circ} \mathrm{W}\right)$ during a geomagnetic storm, Advances in Space Research, 16(5), 27-30, 1995 b.

Fagundes, P. R., Sahai, Y., Bittencourt, J. A., and Takahashi, H., Relationship between generation of equatorial F-region plasma bubbles and thermospheric dynamics, Advances in Space Research, 16(5), 117-120, 1995c.

Fagundes, P. R., Sahai, Y., Bittencourt, J. A., and Takahashi, H., Plasma drifts inferred from thermospheric neutral winds and temperature gradients observed at low latitudes, J. Atmos. Ter. Phys., 58(11), 1219-1228, 1996a.

Fagundes, P. R., Sahai, Y., Takahashi, H., Gobbi, D., and Bittencourt, J. A., Thermospheric and mesospheric temperatures dur- 
ing geomagnetic storms at $23^{\circ} \mathrm{S}$, J. Atmos. Ter. Phys., 58 (16), 1963-1972, 1996b.

Fagundes, P. R., Bittencourt, J. A., Sahai, Y., Takahashi, H., and Teixeira, N. R., Plasma drifts inferred from thermospheric neutral parameters during geomagnetic storms at $23^{\circ} \mathrm{S}$, J. Atmos. Terr. Phys., 60, 1303-1311, 1998.

Gurubaran, S., Sridharan, R., Suhasini, R., and Jani, K. G., Variabilities in the thermospheric temperatures in the region of the crest of the equatorial ionization anomaly - a case study, J. Atmos. Terr. Phys., 57 (6), 695-703, 1995.

Hedin, A. E., Extension of the MSIS Thermospheric Model into the Middle and Lower Atmosphere, J. Geophys. Res., 96, 11591172, 1991.

Hernandez, G. and Roble, R. G., The geomagnetic quiet nighttime thermospheric wind pattern over Fritz Peak observatory during solar cycle minimum and maximum, J. Geophys. Res., 89 (A1), 327-337, 1984.

Hines, C. O., Internal atmospheric gravity waves at ionospheric heights, Can. J. Phys., 38, 1441-1481, 1960.

Meriwether, J. W., Mirick, J. L., Biondi, M. A., Herrero, F. A., and Fesen, C. G., Evidence for orographic wave heating in the equatorial thermosphere at solar maximum, Geophys. Res. Lett., 23 (16), 2177-2180, 1996.
Meriwether, J. W., Biondi, M. A., Herrero, F. A., Fesen, C. G., and Hallenback, D. C., Optical interferometic studies of the nightime equatorial thermosphere: Enhanced temperatures and zonal wind gradients, J. Geophys. Res., 102 (9), 20, 041-058, 1997.

Rees, D., Greenaway, A. H., Gordon, R., McWhirter, I., Charleton, P. J., and Åkesteen, The doppler imaging system: Initial observations of auroral thermosphere, Planet. Space Sci., 12 (3), 273285, 1984.

Sahai, Y., Takahashi, H., Fagundes, P. R., Clemesha, B. R., Teixeira, N. R., and Bittencourt, J. A., Observations of thermospheric neutral winds at $23^{\circ} \mathrm{S}$, Planet. Space Sci., 40, 767-773, 1992a.

Sahai, Y., Takahashi, H., Teixeira, N. R., Fagundes, P. R., Clemesha, B. R., and Bittencourt, J. A., Observations of thermospheric temperatures at $23^{\circ} \mathrm{S}$, Planet. Space Sci., 40, 1545-1549, 1992b.

Sastri, J. H. and Ranganath, H. N. R., Optical interferometer measurements of thermospheric temperature at Kavalur $\left(12.5^{\circ} \mathrm{N}\right.$, 78.5 E), India. J. Atmos. Terr. Physics, 56 (6), 775-782, 1994.

Sipler, D. S., Barry, B. L., and Biondi, M. A., Fabry-Perot determinations of midlatitude F-region neutral winds and temperatures, Planet. Space Sci., 20 (10), 1025-1032, 1982.

Yagi, T. and Dyson, P. L., Measurements of thermospheric temperatures at mid-latitude station, Planet. Space Sci., 33 (2), 203-206, 1985. 